\title{
Fenomenologia e Psicologia Experimental no Início do Século XX
}

\author{
Thiago Gomes de Castro ${ }^{1}$ \\ Pontifícia Universidade Católica do Rio Grande do Sul \\ William Barbosa Gomes \\ Universidade Federal do Rio Grande do Sul
}

\begin{abstract}
RESUMO - O estudo examina as relações entre fenomenologia e psicologia experimental no início do século XX para definir origem, especificidade e abrangência do termo fenomenologia experimental. Inicia com a indicação de que o termo está associado a Carl Stumpf em Berlim. A seguir, acompanha as relações conturbadas entre Husserl e o Departamento de Psicologia da Universidade de Göttingen. Na sequencia constata a influência frutuosa da fenomenologia na psicologia experimental da Universidade de Würzburge na psicologia gestaltálticade Max Wertheimer. A fenomenologia experimental continuou pelos meados do século XX com repercussões na psicologia ecológica de James Gibson. Embora Husserl tenha se distanciado da psicologia experimental, a fenomenologia experimental prosseguiu sem seu aval, subsidiando na atualidade as ciências cognitivas e as neurociências.
\end{abstract}

Palavras-chave:fenomenologia,psicologia experimental,história, método

\section{Phenomenology and Experimental Psychology in the Early Twentieth Century}

\begin{abstract}
This study examines the relationship between phenomenology and experimental psychology in the early twentieth century to define origin, specificity and scope of the term experimental phenomenology. It begins with the statement that the term experimental phenomenology is associated with Carl Stumpf in Berlin. Next, the troubled relation between Husserl and the Departmentof Psychology at the University of Göttingen is described. Then, the fruitful influence of phenomenology on experimental psychology at the University of Würzburg and on Wertheimer's Gestalt psychology is discussed. Experimental phenomenology continued by the mid-twentieth century with repercussions on James Gibson's ecological psychology. Although Husserl has distanced himself from experimental psychology, experimental phenomenology proceeded without his consent, subsidizing contemporary cognitive sciences and neurosciences.
\end{abstract}

Keywords: phenomenology, experimental psychology, history, method

O termo fenomenologia experimental vem levantando questões concernentes a sua legitimidade e coerência com princípios fenomenológicos defendidos por Edmund Husserl. $\mathrm{Na}$ verdade, estudos sobre o movimento fenomenológico (Kockelmans, 1967; Spiegelberg, 1972, 1982) dedicam pouca atenção à experimentação e mais aos desdobramentos existencialista e psicoterapêutico da teoria. Contudo, a fenomenologia experimental permaneceu ativa durante todo $o$ século XX e hoje empresta subsídios às ciências cognitivas e às neurociências. Assim, é oportuno retornarmos ao início do século XX para recuperar as concepções e desenvolvimentos em torno da nascente fenomenologia classificada como uma pré-ciência.

A influência da fenomenologia se notou claramente entre os anos de 1890 e 1910 quando uma comunidade de psicologia experimental se formou nas universidades alemãs. O desafio desses psicólogos foi conciliar as demandas das cadeiras pré-existentes de filosofia com investigações empíricas sobre temas de interesse da filosofia, especialmente nos campo da lógica e teoria do conhecimento (Ash, 1998). Os trabalhos experimentais derivados desses eixos se concentraram em psicologia sensorial e cognição. De acordo com Katz (1950), os psicólogos experimentais pré-gestálticos e os fundadores da Gestalt foram treinados nesse campo de confluências. Para Ash (1998) filósofos-cientistas como Christian von

1 Endereço para correspondência: Rua Fioravante Dalla Stella, $\mathrm{n}^{\circ} 70$, Casa 20, Bairro Cristo Rei, Curitiba, PR, Brasil. CEP: 80.050-150.

E-mail: thiago.cast@gmail.com
Ehrenfels (1856-1932) em Praga, Oswald Külpe (18621915) em Würzburg, e sobretudo Carl Stumpf (1848-1936) em Berlim definiram uma nova direção da mescla entre teoria filosófica e experimentação como um campo próprio da psicologia. Os três viam seus trabalhos como uma nova forma de estabelecer um ponto de vista filosófico alternativo entre o idealismo neo-kantiano e o positivismo. Essa visão, contudo, não foi bem aceita por importantes filósofos do período, como atesta uma petição assinada em 1913 por 106 professores de filosofia. $\mathrm{O}$ grupo de professores foi contra a ocupação de cadeiras em cursos de filosofia por psicólogos experimentais (Araújo, 2013). O documento foi nomeado "Manifesto dos filósofos alemães" e tem o fenomenólogo Edmund Husserl entre seus signatários.

Mesmo com as divergências entre filosofia e ciência no período, a fenomenologia de Husserl foi tomada pela psicologia como teoria renovadora aos estudos em percepção e consciência. Até a primeira metade da década de 1900, Husserl foi bem aceito na comunidade de experimentalistas (Ash, 1998), especialmente por conta da tese sobre a consciência como um processo intencional, enfatizando a descrição da experiência como via de acesso às tendências perceptivas (Husserl, 1901/2001). O conjunto de afirmações agradou um grupo de psicólogos insatisfeitos com as explicações dos fenômenos psicológicos pautadas estritamente em sistemática fisiológica ou teses elementaristas, como na tradição da psicofísica ou em teorias sobre percepção visual como a de Hermann von 
Helmholtz (1821-1894). Não demorou a se notar a influência de Husserl em trabalhos experimentais durante a década de 1900, especialmente nas Universidades de Berlin, Göttingen e Würzburg. Entretanto, como será demonstrado no decorrer do texto, Husserl desaprovou categoricamente a tradução equivocada da sua fenomenologia, pensada enquanto fundação epistemológica,para uma fenomenologia experimental praticada como recurso metodológico pelos psicólogos alemães. Nessa direção, o presente artigo indicará que o modelo epistemológico de fenomenologia adotado pelos psicólogos experimentais no início do século XX seguiu mais o modelo de fenomenologia experimental definido por Stumpf do que o projeto fenomenológico orientado por Husserl.

A exposição está organizada em quatro seções. A primeira aborda a fenomenologia experimental de Carl Stumpf em Berlim. A segunda enfoca a relação de Husserl com o departamento de psicologia da Universidade de Göttingen. A terceira descreve as apropriações da fenomenologia pelo departamento de psicologia experimental da Universidade de Würzburg. A quarta indica as aproximações entre a Gestalt de Max Wertheimer e a fenomenologia descritiva. A observação dos quatro contextos de diálogo evidencia uma proximidade maior da psicologia com a fenomenologia descritiva anterior a Husserl, herança do fisiologista Ewald Hering (18341918) e continuada por Stumpf. Embora Husserl tenha se distanciado da psicologia experimental, a fenomenologia experimental prosseguiu sem seu aval se distanciando do modelo de filosofia primeira, mas com relevante contribuição à ciência.

\section{A Fenomenologia Experimental de Carl Stumpf em Berlim}

Menos restrito à experimentação com fenomenologia foi Carl Stumpf foi o supervisor da tese de habilitação para docência de Husserl na Universidade de Halle (1887) e para quem Husserl dedicou as Investigações Lógicas (1900-1901). Conforme Spiegelberg (1982), Stumpf é o principal responsável por levar a fenomenologia ao uso científico. O filósofo-cientista está associado a um significado de fenomenologia mais híbrido e, portanto, desvinculado da versão purista de filosofia como ciência de rigor indicada, posteriormente, por Husserl. A própria noção de fenomenologia experimental nasce com Stumpf que, além de supervisionar Husserl na Universidade de Halle, orientou as teses de vários psicólogos experimentais em Berlim nas décadas de 1890 e 1900. Diferentemente de Husserl, Stumpf acreditava no valor da pesquisa empírica, e não apenas nos ensaios reflexivos, para a investigação da experiência consciente. Considerava-se um empirista, ao modo de Franz Brentano (1838-1917), e próximo a Gottfried Leibniz (1646-1716) e John Locke (1632-1704).

Os traços da fenomenologia experimental de Stumpf podem ser definidos em cinco características gerais. 1) A matéria da fenomenologia consiste de fenômenos primários e secundários; 2) A Fenomenologia é uma ciência neutra ou pré-ciência; 3) A Fenomenologia é a primeira das pré-ciências neutras; 4) A Fenomenologia não é uma disciplina independente para especialistas, mas sim a primeira camada no estudo de cada ciência já estabelecida; 5) A Fenomenologia, enquanto ciência descritiva, tem de ser estudada por todos os métodos cabíveis, incluindo o experimental. Essas características foram apresentadas pelo pesquisador em 1905 na defesa de seu tratado de classificação das ciências na Academia Prussiana de Ciências - Berlim ${ }^{1}$ ${ }^{2}$. As cinco características serão definidas a seguir como apresentadas por Spiegelberg (1982). Convém antecipar, como já informado na característica dois, que Stumpf trabalhava com a premissa de três pré-ciências, as quais seriam a Fenomenologia, a Eidologia e a Teoria das Relações.

$\left(1^{a}\right)$ A matéria da fenomenologia consiste de fenômenos primários e secundários - Por fenômeno Stumpf entendia os correlatos objetivos dos fenômenos psíquicos ou atos, conforme nomenclatura de Brentano. Contudo, diferente de Brentano, Stumpf não negava a realidade desses fenômenos correlatos objetivos, enfatizando que enquanto conteúdos eles são tão reais quanto os fenômenos psíquicos. Stumpf não endereçou a questão da independência entre as funções subjetivas e os correlatos objetivos (dualismo), resguardando tal tarefa às ciências físicas. Por fenômenos primários Stumpf entendeu aqueles conteúdos da experiência imediata que são tomados pelos sentidos. Por fenômenos secundários entendeu as imagens dessa experiência original tal qual ocorre na memória. Os fenômenos para Stumpf não incluem os conteúdos que são formados pela consciência, mas apenas os que são dados à consciência pelos sentidos. Sendo assim, fenômenos como agregados, conceitos, conteúdos de julgamento e valores - chamados por Stumpf de constructos - seriam alvo de outro campo de investigação, nomeado Eidologia. Percebe-se aqui claro conflito entre a fenomenologia de Husserl, muito dedicada aos "constructos", e a fenomenologia de Stumpf pautada na experiência imediata do campo dos sentidos. A fenomenologia de Stumpf também não contemplaria relações entre os fenômenos e os constructos, que por sua vez, seria parte do campo de estudos da Teoria das Relações.

(2a) A Fenomenologia é uma ciência neutra ou préciência - Stumpf considerava a fenomenologia como uma fundação indispensável às ciências naturais e humanas. Sua tarefa seria a análise e descrição dos conteúdos imediatos dos nossos atos ou funções, o estudo de suas relações internas e de suas leis estruturais preparatórias para o estudo das suas dependências causais com fatores outros que não o próprio fenômeno. Stumpf destaca o fisiologista Ewald Hering (18341918) como o primeiro a delinear a necessidade de uma préciência, etapa anterior à explicação das condições causais que interferem na percepção dos fenômenos. Conforme Spiegelberg (1982), para Hering o primeiro requisito ao estudo científico das cores, por exemplo, é a condução de uma análise conscienciosa e arranjos sistemáticos baseados exclusivamente na apreciação qualitativa da manifestação dos fenômenos, nesse caso na descrição das propriedades das cores nelas mesmas. Essa observação levou Hering a um axioma de quatro pares de cores contrastantes. Só então,

1 Stumpf, C. "Zur Einteilung der Wissenschaften" - Preussischen Akademie der Wissenschaften, Berlin 1906 
a partir dessa descrição, podem-se derivar os nexos causais entre as relações de constructos estabelecidas na experiência composta das cores. A metodologia de Hering é anterior a de Husserl, ainda que o fisiologista não tenha utilizado o termo "fenomenologia".

$\left(^{a}\right)$ A Fenomenologia é a primeira das pré-ciências neutras - Para Stumpf as três pré-ciências seriam a Fenomenologia, a Eidologia e a Teoria das Relações. A Fenomenologia é a primeira porque nenhum constructo (Eidologia) pode ser construído sem o material derivado da experiência dos fenômenos, e nenhuma relação pode pressupor, direta ou indiretamente, essa experiência original dos fenômenos dentro da qual as relações estão contidas e acontecem (Teoria das Relações).

(4 $\left.{ }^{a}\right)$ A Fenomenologia não é uma disciplina independente para especialistas, mas sim a primeira camada no estudo de cada ciência já estabelecida - Stumpf não desejava a fenomenologia isolada em cadeiras acadêmicas especiais e enclausurada no exercício filosófico da nova pré-ciência. Seu plano envolvia subordinar a fenomenologia às tradicionais, estendendo suas ações entre físicos, fisiologistas e psicólogos. A fenomenologia deveria ser, portanto, o estágio básico da pesquisa científica para então seguir à investigação das propriedades causais e dependências dos fenômenos em fatores outros que não o próprio fenômeno.

( $\left.5^{\mathrm{a}}\right)$ AFenomenologia, enquanto ciência descritiva, tem de ser estudada por todos os métodos cabíveis, incluindo o experimental - A fenomenologia experimental no trabalho de Stumpf pode ser exemplificada com suas investigações sobre o som. Ao pesquisar as propriedades fundamentais de tons musicais simples Stumpf não apenas prestou atenção ao pitch, intensidade e qualidade do tom, mas também às condições experimentalmente variadas sob as quais as propriedades do fenômeno aparecem. O estudo em fenomenologia experimental inclui a investigação do estímulo físico e novos métodos para controla-los. O propósito aí é permitir a seleção precisa na apresentação do fenômeno, de modo a favorecer tanto a observação e descrição do fenômeno como também a sua variação. Segundo Spiegelberg (1982), esse entendimento de fenomenologia recebeu críticas de um lado, mas por outro abriu caminhos para a sua aplicação experimental, com bons resultados, na psicologia científica.

As diferenças entre as fenomenologias de Husserl e Stumpf são marcantes, porém alguns pontos compartilham solo comum ou pelo menos conexões. Ambos buscavam iniciar por uma descrição sem vieses da experiência imediata do fenômeno. Ambos procuravam mais do que meras generalizações empíricas e queriam estudar as estruturas essenciais no e entre os fenômenos. Os dois reconheciam o processo das estruturas lógicas como separado de meros atos psicológicos (psicologismos). Para Husserl (1913/2006), contudo, o uso do termo fenomenologia por Stumpf tinha um significado completamente diferente do seu. Segundo o filósofo, a fenomenologia de Stumpf era mais limitada em escopo, pois excluía as funções e atos (constructos) do campo fenomenológico de investigação, parte essencial nos escritos de Husserl na fase das Investigações Lógicas (1901/2001). As versões também se distanciam quando Stumpf se restringe a análise do material bruto da experiência sensorial (Hylé - dado sensível) e não abarcava a propriedade noética da intencionalidade, que, para Husserl até meados da década de 1910, distingue-se da experiência sensorial bruta por dar forma ao fluxo de experiências (Sokolowski, 1970).

Além disso, Stumpf não contempla a redução fenomenológica, recurso essencial na fenomenologia de Husserl após 1905, como via metodológica ao estudo das essências no fluxo de experiências. Na própria definição do escopo da psicologia fenomenológica de Husserl notamse as diferenças de projeto para Stumpf. Segundo Husserl (1977, p.33-34) as características básicas de uma psicologia de cunho fenomenológico deveriam ser: a) seu caráter apriorístico às ciências de fato, b) seu cunho eidético, c) seu traço descritivo puro, e d) a análise da intencionalidade, traço distintivo universal do ser psíquico. A semelhança de sentido assumida por Stumpf aqui é o de uma psicologia descritiva, porém mais próxima ao modo metodológico descritivo da pré-ciência de Hering. Além de Stumpf, outro proponente de uma psicologia com base fenomenológica nesse período foi Georg Elias Müller (1850-1934), chefe da cadeira de psicologia experimental da Universidade de Göttingen entre 1881 e 1921 (Ash, 1998).

\section{A Fenomenologia Experimental de Georg Elias Müller em Göttingen}

Müller estabeleceu um programa de psicologia experimental dedicando-se principalmente à investigação empírica da memória. O sentido fenomenológico adotado por G.E. Müller foi o da fenomenologia como psicologia descritiva, associado à transposição metodológica da fenomenologia de Husserl. Spiegelberg (1972) relata, contudo, que Husserl não aprovava o uso da fenomenologia conforme Müller e o departamento de psicologia de Göttingen. De seu lado, Müller considerava a resistência de Husserl em relação às inovações empíricas como um isolamento não produtivo e que sua forma de filosofar seria um modo de preciosismo verbal.

As divergências entre Husserl e os psicólogos experimentais de Göttingen foram captadas com elegância pelo psicometrista C. E. Spearman, em sua autobiografia, referindo-se à visita que fez à Universidade de Göttingen em 1906. Spearman discorreu sobre Husserl, após descrever suas impressões das aulas de Müller:

Na mesma universidade, a de Göttingen, eu tive a vantagem adicional de assistir as palestras de Husserl, em seu modo, um grande homem como G.E. Müller.Mas rumos seguidos por eles os levaram a mundos à parte.Na verdade, a única coisa que parecia comum aos dois era a inabilidade de um apreciar o outro! Para Müller, as análises refinadas de Husserl pareciam ser um renascimento da idade média (como, de fato, elas amplamente foram, mas não necessariamente como uma desvantagem). Para Husserl, as tentativas de Müller em lidar com os problemas psicológicos por meio de experimentação era como tentar desvendar rendas com um tridente. Ainda assim, o procedimento de Husserl - como ele o descreveu para mim - apenas diferia daquele usado pelo melhor experimentalista, lidando com problemas similares, em que pesa Husserl não ter ninguém além dele mesmo como sujeito experimental. (Spearman, 1930 citado por Spiegelberg, 1972, p. 35). 
Mesmo trabalhando com problemas similares, como atesta Spearman na citação, Husserl mantinha uma forte preocupação em definir um programa filosófico sólido o suficiente para se afastar das proposições empíricas embasadas em um tipo de racionalismo que ele discordava. O projeto que Husserl seguiu foi o de uma filosofia primeira como refundação epistemológica para as ciências naturais, mas através de exercícios lógicos transcendentais e não empíricos. Nesse sentido, seu desentendimento praticamente generalizado com a psicologia da época pode ser compreendido a partir do panorama dessa busca de refundação pela via estrita da filosofia. A psicologia experimental do período entendia que sua fundação epistemológica deveria ser alimentada por constatações empíricas, amparada em lógicas empiristas eholistas, porém não necessariamente de orientação positivista ou naturalista. Nessa direção, a consolidação da psicologia como ciência independente passava necessariamente pela aquisição de provas empíricas, tendo dificuldade em pautar ou fundamentar sua investigação, nesse momento, pela via da filosofia primeira fenomenológica. O projeto epistemológico inacabado da fenomenologia husserliana, nesse cenário, forçava um compromisso conceitual à psicologia que a nova ciência não estava disposta a encampar.

Desse primeiro contato entre Husserl e a psicologia experimental em Göttingen, Spiegelberg (1972) destaca, por exemplo, o caráter indireto das apropriações da fenomenologia pela experimentação. Ou seja, ainda que os psicólogos vissem um forte potencial na fenomenologia para a reestruturação dos métodos de estudo da percepção, resistiam ao abandono da experimentação em si. A força da empiria é uma característica do Círculo de Göttingen e Husserl desmereceu invalidou a via descritiva da fenomenologia como recurso metodológico nesse contexto. Spiegelberg (1972) chega a ensaiar uma escala de proximidade do projeto fenomenológico de Husserl às teses psicológicas desenvolvidas por seus alunos em Göttingen. Wilhelm Schapp (1884-1969) e Heinrich Hofmann (1883?) escreveram estudos sobre percepção de cores e sensação, influenciados pela fenomenologia de Husserl, porém sem aporte experimental para as conclusões. Em contraste, David Katz (1884-1953), Edgar Rubin (1886-1951), Erich Jaensch (1883-1940) e Géza Révész (1878-1955) tomaram as influências fenomenológicas em diferentes níveis, amparando-se em investigação experimental. A ilustração abaixo reproduz a descrição do historiador:

Ao contrário do laboratório de Leipzig, coordenado por Wilhelm Wundt (1832-1920), em Göttingen a nova teoria fenomenológica na experimentação procurava se distanciar da introspecção para as explicações sobre o funcionamento global da consciência. Wundt e os psicólogos de Leipzig são inclusive criticados por Husserl em 1907, durante seu período em Göttingen, no tocante à questão da distinção entre percepção e apercepção. Como se sabe, o termo percepção refere-se ao processo de conhecimento de objetos e eventos por meios sensoriais. Em contraste, o termo apercepção, de Leibniz a Wundt, foi entendido como o processo no qual o conteúdo era focalizado mais claramente para a compreensão, posterior à percepção (Klein, 1970). A insistência de Husserl (1907/1997), no entanto, foi enfatizar a percepção como processo ativo vinculado à intencionalidade. $\mathrm{O}$ entendimento da época para apercepção sugeria certa passividade e

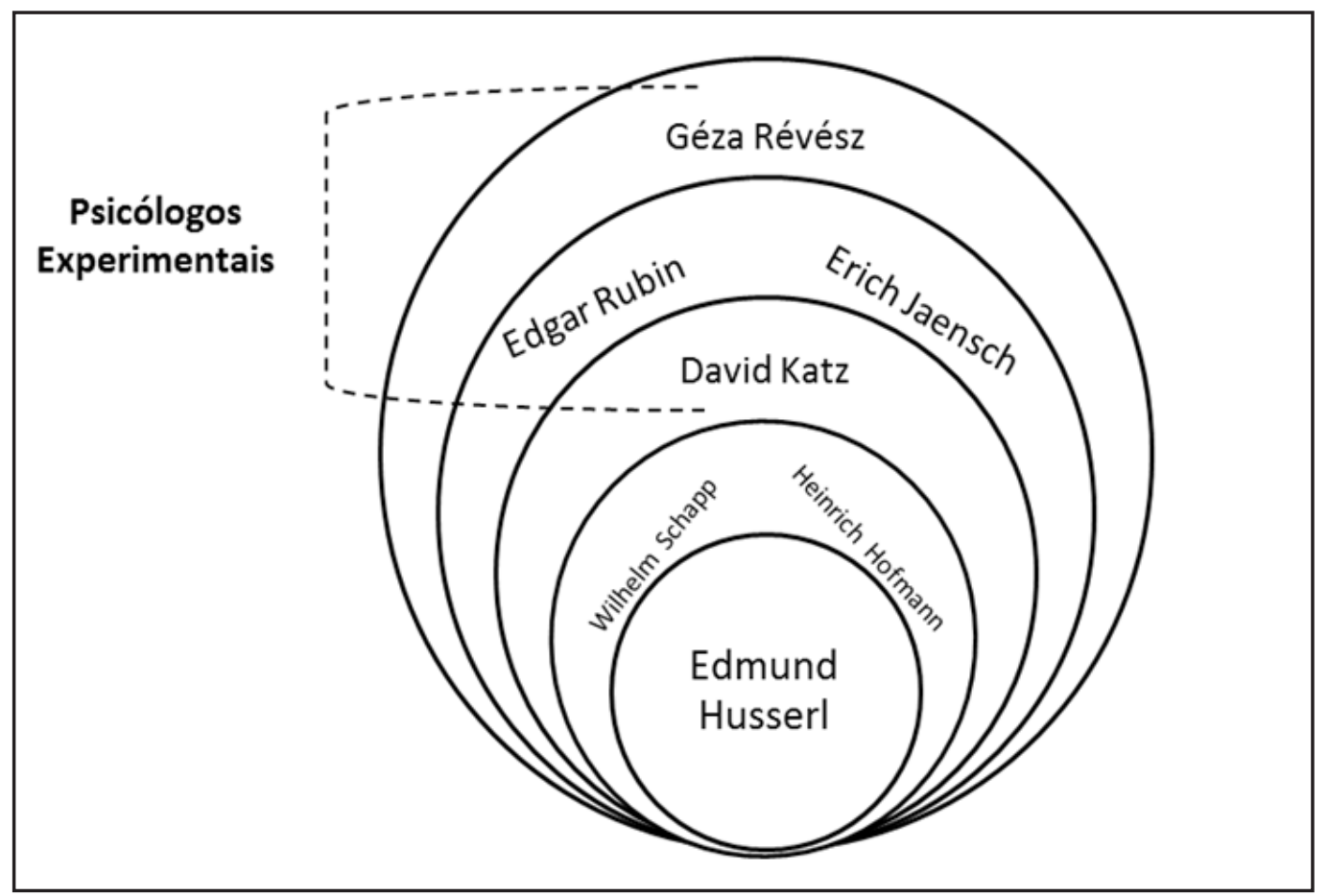

Figura 1. Grau de proximidade de Husserl com estudantes de Göttingen trabalhando em temas psicológicos - Círculo de Göttingen (Spiegelberg, 1972). 
independência entre percepção e intencionalidade. Segundo o filósofo, tal entendimento passivo da apercepção já havia sido suplantado pelo conceito de apreensão de Stumpf. De acordo com Husserl, Stumpf entende que a ideia de apercepção seria insuficiente dentro de uma compreensão intencional da percepção, sendo mais adequado falar de um modo particular do organismo, algo como uma tendência de acesso às evidências, enquanto apreensão ativa das coisas. Similar a essa proposição ativa de Stumpf é o conceito de intencionalidade operante de Husserl (Husserl, 1913/2006).

Um exemplo de derivações distintas ao projeto de Husserl nesse período são Wilhelm Schapp e Oswald Külpe. Schapp foi ouvinte das conferências de 1907 de Husserl em Göttingen, tendo realizado sua tese sobre a análise intencional da percepção de cores, trabalho de característica puramente conceitual e alinhado com a análise eidética transcendental proposta pela fenomenologia filosófica. Na mesma época, o psicólogo Külpe, aluno de Wundt, buscava desenvolver um programa de psicologia experimental na Universidade de Würzburg, baseado em uma fenomenologia descritiva e entendida como ciência de realidades (Spiegelberg, 1972). Külpe foi o orientador da tese de Max Wertheimer (18801943), cofundador da Psicologia da Gestalt, também na década de 1900. A propósito, convém lembrar que os outros dois conhecidos cofundadores da Gestalt, Köhler e Koffka foram orientados por Stumpf, em Berlim. Acompanhando G.E. Müller e Stumpf, Külpe mantinha restrições à direção da filosofia fenomenológica delineada por Husserl, considerando-a importante, mas metodologicamente imperfeita no tratamento da realidade.

Ainda que notórias as diferenças de propósito entre Husserl e os psicólogos alemães da década de 1900, percebese entre os autores uma forte tendência no combate às teses psicofísicas vigentes. Enquanto Husserl fazia esforços para suplantar a epistemologia das investigações baseadas no sensorialismo, alguns psicólogos enfrentavam o desafio de criar condições experimentais e leis de interpretação diferenciadas, fundadas em compreensão holista e integrada sobre o funcionamento consciente e na direção de uma lógica descritiva fenomenológica (Ash, 1998). Nesse momento, o destaque que Husserl confere à intencionalidade para a percepção mantém conexão indireta com as modalidades inovadoras de pesquisa de percepção espacial que os discípulos de Müller, Külpe e Stumpf irão desenvolver nas décadas seguintes.

\section{Apropriações do método fenomenológico pela psicologia experimental em Würzburg}

De acordo com Pillsbury (1911), o uso mais direto do método fenomenológico de Husserl na psicologia alemã encontra-se no trabalho de Oswald Külpe e seus estudantes na Universidade de Würzburg. Os psicólogos em Würzburg estavam interessados, na década de 1900, no estudo empírico do pensamento, mais especificamente nos conteúdos psíquicos que engrenam os atos do pensamento, diferentemente de sensações, imagens e sentimentos como sugeridos pelo método introspectivo em Leipzig com Wundt. Külpe defendeu sua tese sob a orientação de Wundt, mas abandonou o método de seu orientador para se aproximar à proposta de Husserl.

Nos anos de 1904 e 1905 em Würzburg, Narziss Ach (1871-1946), Henry Watt (1879-1925) e Oswald Külpe conduziram experimentos para investigar o efeito das instruções de experimentadores sobre a disposição do pensamento em participantes durante tarefas de resolução de problemas. De acordo com Watt (1905/1964) as instruções produziam um preparo mental que incide dinamicamente no pensamento dos participantes, chegando a criar o que Ach denominou de "determinações de tendências" perceptivas pela focalização do pensamento em aspectos sugeridos nas instruções. Na prática, a determinação das tendências perceptivas pela instrução (ex. focalizar a cor de palavras apresentadas) aumenta a acurácia de identificação dos estímulos pelas propriedades específicas, independente de quantas vezes o estímulo foi apresentado anteriormente. A resolução do problema é facilitada pela manutenção do foco em características peculiares do estímulo.

Em 1906 e 1907 August Messer (1867-1937) e Karl Bühler (1879-1963) introduziram o vocabulário de Husserl e seu modelo de consciência na escola de Würzburg (Ash, 1998). Messer identificou no ato intencional, definido por Husserl, o elemento sem imagem que dá sentido ao mundo da consciência. Bühler, por sua vez, distinguiu três classes de conteúdos de pensamento: a) pensamentos simples, ou correlatos de conteúdos que seriam as determinações de tendência de Ach; b) pensamentos de memória, caracterizados pela consciência de uma regularidade (interpretação das retenções de Husserl); e c) intenções, nas quais o ato de significar deriva do que está adiante e não do que já foi significado (interpretação das protenções de Husserl). Conforme Pillsbury (1911), Bühler estava tentando deliberadamente submeter a fenomenologia de Husserl ao teste experimental. Para Külpe (1912) a diretividade do pensamento - interpretação derivada da noção de intencionalidade de Husserl - seria a pré-condição para a ocorrência do pensamento em si e se tornou uma base de sua epistemologia.

Os experimentos da escola de Würzburg foram criticados por Wundt, que considerou os procedimentos de seu aluno muito sugestionáveis a inferências e pouco rigorosos, denominando os trabalhos como "pseudoexperimentos" (Danziger, 1980). Ernst Cassirer (1910/1923), indicando abertura à Gestalt, também criticou os experimentos de Würzburg, pois considerou que os métodos adotados tratavam os processos e conteúdos do pensamento como novas unidades reflexivas, tal qual no elementarismo criticado pelo próprio Külpe, ao invés de tratar o processo do pensamento como um todo (Holismo experimental). Para Cassirer, a experiência consciente poderia ser investigada pelas ciências ou como um elemento agregado de explicações físicas ou como um sistema dinâmico integrado ao corpo. A indicação da escola de Würzburg seguiria o padrão de tratamento do pensamento ou consciência como um agregado, ainda que almejasse a experiência como ocorrência estendida no tempo. Por outro lado, a indicação da fenomenologia e da Gestalt seria a da consciência como um sistema dinâmico, em que as ocorrências experienciais não são sujeitas à secção derivativa. 
Segundo Ash (1998), Külpe e seus alunos se debruçaram sobre o método de Husserl e seu modelo de cognição como forma de embasar uma posição de centro na filosofia do período, entre o tradicional empirismo baseado em sensações e o idealismo, sem com isso comprometer o método experimental. Husserl (1907/1997), como já havia feito em Göttingen, logo tratou de desaprovar o uso da fenomenologia como psicologia descritiva em Würzburg. O filósofo alegou que estava interessado na natureza metafísica e não no estudo experimental da consciência. Para Husserl (1911/1965) os procedimentos experimentais só poderiam fornecer leis provisórias sobre o alcance de variação de determinadas experiências conscientes em condições específicas, mas não sua essência em fluxo.

\section{Derivações experimentais da Fenomenologia para a Psicologia da Gestalt}

Outra frente de apropriação da fenomenologia, em um sentido descritivo, na psicologia experimental do início do século XX é o trabalho de Max Wertheimer sobre a aparência de movimento, denominado fenômeno Phi. Em 1912 Wertheimer publicou um artigo, demonstrando que a apresentação de dois estímulos isolados e estáticos, dispostos em intervalos de sequenciamento controlados, produz a sensação de movimento como se os dois estímulos fossem um só colocado em movimento. A ilusão depende do balanço temporal entre a apresentação do primeiro estímulo e do segundo estímulo. Este efeito ilusório tornase mais interessante quando os participantes são expostos repetidamente a um intervalo entre os estímulos um pouco superior a 60 milissegundos. Nessa condição os participantes percebem movimento, pois a transição entre os estímulos não é demarcada claramente (efeito de unidade dos estímulos em movimento criada pela alta velocidade de transição). Segundo Wertheimer (1912) o fenômeno Phi é apenas um processo, uma transição, é um evento dinâmico não estático na natureza e não pode ser derivado dos conteúdos ópticos usuais.

$\mathrm{Na}$ versão associacionista de movimento, deriva-se a aparência de movimento a partir do retrato de um objeto em diferentes posições sucessivas. Segundo essa versão, ocorreria uma projeção subjetiva do individuo na sucessão do mesmo objeto, o que daria sentido de movimento coerente. Desse modo, o mesmo objeto em movimento teria que ser visto pelo menos em duas posições. Para Wertheimer (1912) o fenômeno $P h i$, diferente da versão associacionista, indica a hegemonia da experiência global do sujeito na percepção do movimento: primeiro o indivíduo vê o movimento, e não um objeto que primeiro está em um lugar e depois em outro. O que rege a sensação de movimento é a dinâmica de transição e ritmo entre elementos semelhantes, mas não necessariamente idênticos.

A relação entre o experimento de Wertheimer e a fenomenologia experimental é destacada por Koffka (1931), que avalia a contribuição do colega como um achado sobre a experiência genuína de movimento não derivada de causação linear entre unidades objetivas, mas de uma organização de totalidade entre os elementos que só fazem sentido quando tomados ativamente pelo organismo. Segundo Koffka, o fenômeno $P h i$ não poderia ser explicado por teorias com base em pura simultaneidade de eventos ou pura sucessão de eventos temporais. A especificidade da experiência de movimento, tomada como totalidade da relação entre elementos distintos apresentados, indicaria um novo caminho para o estudo dos processos perceptivos. Um caminho pautado nas propriedades de organização e distribuição de similitudes intervalares, temporal e espacial, num campo de percepção (Gestalten).

O experimento do fenômeno Phi indica uma fenomenologia experimental pela ênfase na experiência descritiva dos participantes diante dos estímulos. Mais importante do que isso, foi um estudo fenomenológico por orientar a investigação pela observação sem postular teorias prévias sobre o funcionamento cognitivo (Wertheimer, 1912). A utilização de instrumentos de precisão e condições experimentais controladas cuidadosamente não descaracterizou o viés fenomenológico da pesquisa, pois o instrumento chave continuou sendo o observador e sua descrição dos achados. Conforme Luccio (2010), mesmo assumindo o caráter investigativo de uma fenomenologia experimental, não é possível associar os pressupostos da Gestalt experimental aos interesses de uma teoria representacional, no que diz respeito à mediação da consciência na produção de realidades, como na fenomenologia de Husserl. A fenomenologia experimental é, portanto, no caso de Wertheimer, uma heurística estritamente metodológica, e não uma orientação pelas teses da filosofia fenomenológica.

Wertheimer se diferenciou como fenomenólogo experimental por indicar um interesse na experiência perceptiva sem aplicar conceitos psicológicos para confirmar hipóteses fisiológicas, como na tradição de Hermann von Helmholtz (1821-1894). Tampouco utilizou linguagem fisiológica para amparar achados de fenomenologia experimental, como na tradição de Stumpf (Sinico, 2010). A relação da lógica da fenomenologia experimental com a Gestalt não seria unânime, segundo Luchins e Luchins (1999), pois nota-se uma maior força das hipóteses fisiológicas sobre a interpretação dos achados experimentais em Wolfgang Köhler (1887-1967). De acordo com os autores, Wertheimer e Köhler não compartilhavam do mesmo entendimento de isomorfismo, por exemplo. Wertheimer estava mais interessado na fenomenologia da percepção como passo inicial da análise, para então criar modelos fisiológicos que se encaixassem a esses resultados. Só a partir da fenomenologia esses modelos poderiam ser criados para então servir de guia em pesquisas futuras. Sua versão de isomorfismo é mais funcional. Köhler, por sua vez, estava mais interessado no emparelhamento definitivo do funcionamento fisiológico com o perceptivo ou psicológico, sendo assim mais suscetível às hipóteses fisiológicas. Seu isomorfismo é psiconeural. Mesmo com a diferença entre os autores, em ambos os casos a teoria é monista, pois as duas faces - fenomenologia e fisiologia - seriam maneiras de se olhar a mesma coisa (Engelmann, 2002). Não faria mais sentido falar em subjetivo e objetivo na Psicologia da Gestalt, noções estas trabalhadas com detalhamento por Stumpf, Külpe e Husserl. 


\section{Considerações Finais}

De acordo com Ash (1998) as discussões sobre psicologia experimental na Alemanha entre os anos de 1890 e 1967 foram pautadas pela divisão entre abordagens holistas e atomistas no estudo da percepção. Por holismo entendese a explicação sobre percepção baseada nas relações de aspectos contíguos em um campo perceptivo. Por atomismo entendem-se as teses fundamentadas no nível de excitação de sensores perceptivos individualizados para a ativação de impressões sensoriais. No panorama holistaencontravam-se os psicólogos identificados com a herança fenomenológica e desenvolvimentos gestálticos, enquanto que do lado atomista destacaram-se os pesquisadores da psicofísica alinhados com teses sensoriais centralizadas sobre o funcionamento da percepção.

Nesse contexto histórico de afirmação dos métodos experimentais na psicologia a fenomenologia despontou como possível via de fundamentação de práticas mais integradas com a experiência consciente dos sujeitos. As evidências históricas indicam que a experimentação serviu não apenas como um dos eixos de aplicação da fenomenologia à psicologia, mas provavelmente como o primeiro propulsor de interesse da psicologia pela literatura fenomenológica. O grupo de cientistas descritos no texto buscou, cada qual a sua maneira, essa aproximação experimental com a fenomenologia. Como ficou evidente, havia grande interesse da psicologia na nova teoria fenomenológica de Husserl, mas o filósofo foi refratário a todas as investidas experimentais. Os psicólogos não se abateram pelo conflito e seguiram suas investigações refinando seus métodos sem se preocupar com a manutenção de uma lógica fenomenológica estrita ao modo de Husserl.

A noção de fenomenologia assume outras características quando enunciada nos trabalhos dos psicólogos experimentais. Em muitos casos uma fenomenologia mais influenciada por Ewald Hering e Stumpf do que por Husserl (Ash, 1998; Spiegelberg, 1972, 1982). Em Stumpf aparece como uma pré-ciência interessada em fenômenos correlatos objetivos tomados imediatamente pelos sentidos do corpo, e não restrita à filosofia, mas integrada com as outras ciências, incluindo o método experimental em seu escopo. Por G.E. Müller como um método descritivo necessário à elaboração de um programa experimental que se oriente por princípios funcionais diferentes do laboratório de Leipzig. Por Oswald Külpe como teoria fundamental para a construção de uma nova epistemologia experimental e apropriação direta de conceitos Husserlianos para o embasamento de conceitos psicológicos. E por Max Wertheimer como heurística inicial para a observação dos fenômenos perceptivos, sem recorrer às teses fisiológicas ou conceitos psicológicos já estabelecidos.

Conforme Sinico (2010), quando se trata de psicologia da percepção, a psicologia experimental da Gestalt e, em alguma medida, a psicologia ecológica de James J. Gibson (19041979) orientam-se por critérios nômicos, determinísticos e modais. De acordo com o autor a disciplina referencial para esse domínio é a fenomenologia experimental. Nesses campos os dados observáveis são tomados como explanações de um conteúdo direto e imediato da experiência. O domínio da fenomenologia experimental é nômico porque o seu objetivo é o conhecimento baseado na formulação de leis. É determinístico porque, mesmo que com um caráter de relações lógicas não causais, denota uma classe de fenômenos sob investigação totalmente determinados por dinâmicas de campo e não por processamentos secundários. Por fim, o domínio é modal em função das condições de necessidade inscritas nas relações entre as variáveis perceptuais.

Considerando essas particularidades do domínio da fenomenologia experimental, poderíamos nos precipitar afirmando que tal modelo de investigação é incompatível com modelos de pesquisa bem estabelecidos na ciência tradicional. De fato, a disciplina não pretende estabelecer causas hipotéticas que subjazem as regularidades obtidas nas observações diretas e imediatas da experiência. No entanto, como bem aponta Sinico (2010), isso não significa que ciências como as Ciências Cognitivas e as Neurociências não possam obter vantagem ao incorporar o conhecimento derivado da fenomenologia experimental. Pelo contrário, tal conhecimento seria necessário para uma explicação exaustiva, uma vez que o objetivo dessas ciências é investigar o sistema perceptivo e adotar coerentemente um modelo teleológico-funcional de explicação. Por modelo teleológico-funcional de explicação entende-se a prática de identificar e tornar explícito as condições que permitem a atuação de uma função perceptiva e não apenas uma descrição dos mecanismos. Nesse sentido, não se trata de descrever o funcionamento normal de um sistema, mas sim todas as condições de variação dessa funcionalidade. Assim, o conhecimento dos fenômenos observáveis em sua variação pela fenomenologia experimental, seja em setting experimental ou em contextos naturais, é essencial para as ciências contemporâneas.

\section{Referências}

Araújo, S. F. (2013). Ecos do passado: Estudos de história e filosofia da psicologia. Juiz de Fora, MG: Editora UFJF.

Ash, M. G. (1998). Gestalt psychology in german culture, 18901967: holism and the quest for objectivity. New York: Cambridge University Press.

Cassirer, E. (1923). Substance and function. Chicago, IL: Open Court Publishing Company. (Trabalho original publicado em 1910)

Danziger, K. (1980). The history of introspection reconsidered. Journal of the History of the Behavioral Sciences, 16, 241-262.

Engelmann, A. (2002). A psicologia da gestalt e a ciência empírica contemporânea. Psicologia: Teoria \& Pesquisa, 18(1), 1-16.

Husserl, E. (1965). Philosophy as rigorous science (Q. Lauer, Trans.). New York: Harper \& Row Publishers. (Trabalho original publicado em 1911)

Husserl, E. (1977). Phenomenological psychology: lectures, summer semester 1925 (Husserliana IX). The Hague: Martinus Nijhoff. (Trabalho original publicado em 1962)

Husserl, E. (1997). Thing and space: lectures of 1907. Netherlands: Kluwer Academic Publisher. (Original publicado em 1973)

Husserl, E. (2001). Logicalinvestigations. Florence: Routledge. (Trabalho original publicado em 1901) 
Husserl, E. (2006). Idéias para uma fenomenologia pura e para uma filosofia fenomenológica. São Paulo: Idéias \& Letras. (Trabalho original publicado em 1913)

Katz, D. (1950). Gestalt psychology: its nature and significance. New York: The Ronald Press Company.

Klein, D. B. (1970). A history of scientific psychology. New York: Basic Books.

Kockelmans, J. J. (1967). Phenomenology. New York: Anchor Books.

Külpe, O. (1912). Die realisierung: ein beitrag zur grundlegung der realwissenschaften, Volumen 1. Leipzig: S. Hirzel.

Koffka, K. (1931). Beginnings of gestalt theory. Archives of the History of American Psychology, Box M379.

Luccio, R. (2010). Anent isomorphism and its ambiguities: from Wertheimer to Köhler and back to Spinoza. Gestalt Theory, 32(3), 219-262.

Luchins, A. S., \&Luchins, E. H. (1999). Isomorphism in gestalt theory: comparison of Wertheimer's and Köhler's concepts. Gestalt Theory, 21(3), 208-234.

Pillsbury, W. B. (1911). The essentials of psychology. New York: Mcmillan.
Sinico, M. (2010). Explanation in experimental phenomenology: the nomic, deterministic and modal domain. Gestalt Theory, 32(4), 293-306.

Sokolowski, R. (1970). The formation of Husserl's concept of constitution. The Hague: Martinus Nijhoff.

Spiegelberg, H. (1972). Phenomenology in psychology and psychiatry: a historical introduction. Evanston: Northwestern University Press.

Spiegelberg, H. (1982). The phenomenological movement: a historical introduction. Boston, MA: MartinusNihjhoff.

Watt, H. J. (1964). Experimental contribution to a theory of thinking. Em J.M. Mandler \& G. Mandler, Thinking: from Association to Gestalt (pp. 189-200). New York: Wiley. (Trabalho original publicado em 1905)

Wertheimer, M. (1912). Experimentelle studien über das sehen von bewegung. Zeitschrift für Psychologie und Physiologie der Sinnesorgane, 61, 161-265.
Recebido em 10.09.2013

Primeira decisão editorial em 20.01.2015

Versão final em 27.01.2015

Aceito em 01.03.2015 